\begin{tabular}{|c|l|}
\hline Title & Classification of Oxidation Behavior of Disilicides \\
\hline Author(s) & Kurokawa, Kazuya; Y amauchi, A kira \\
\hline Citation & Designing of Interfacial Structures (Solid State Phenomena: 127), 227-232 \\
\hline Issue Date & 2007 \\
\hline Doc URL & http://hdl.handle.net/2115/17156 \\
\hline Rights & the original is available online at www.scientific.net \\
\hline Type & article (author version) \\
\hline File Information & SSP127.pdf \\
\hline
\end{tabular}

Instructions for use 


\title{
Classification of Oxidation Behavior of Disilicides
}

\author{
Kazuya Kurokawa and Akira Yamauchi \\ Center for Advanced Research of Energy Conversion Materials, Hokkaido University \\ Kita 13 Nishi 8, kita-ku, Sapporo 060-8628, Japan \\ kurokawa@eng.hokudai.ac.jp \\ akira-y@eng.hokudai.ac.jp
}

Keywords: Disilicide, High temperature oxidation, Structure of oxide scale, Classification of oxidation behavior

\begin{abstract}
This study focuses on classification of structures of oxide scales formed on disilicides. The oxide scales formed on disilicides can be grouped into 3 types, (a) silica scale, (b) mixed oxide (silica+metal oxide) scale, and (c) double layered (silica/metal oxide) scale. Disilicide that forms an oxide scale of the type (a) generally show excellent oxidation resistance. As such disilicides, there are $\mathrm{FeSi}_{2}, \mathrm{CoSi}_{2}, \mathrm{MoSi}_{2}$, WSi $\mathrm{W}_{2}$, etc. In $\mathrm{FeSi}_{2}$ and $\mathrm{CoSi}_{2}$, a protective silica scale must be formed due to the selective oxidation of $\mathrm{Si}$, whereas in $\mathrm{MoSi}_{2}$ and $\mathrm{WSi}_{2}$ evaporation of metal oxide plays an important role for the formation of a silica scale. Oxidation of $\mathrm{TaSi}_{2}$ and $\mathrm{NbSi}_{2}$ belonged to the type (b), and only $\mathrm{CrSi}_{2}$ the type (c).
\end{abstract}

\section{Introduction}

Disilicides such as MoSi2 are receiving much attention as high-temperature materials because of the extremely-high oxidation resistance based on formation of a protective silica scale. However, oxidation mechanism of disilicides has not been clarified yet. In other words, thermodynamic and kinetic conditions for formation of a protective silica scale are not well-known.

In the field of advanced jet engines and gas turbines, development of ultra-high temperature structural materials is indispensable. Disilicides are expected to be promising candidate materials because of high melting point and relatively low density. Moreover, Some refractory metal disilicides, for example $\mathrm{MoSi}_{2}$ [1-3] and $\mathrm{WSi}_{2}$ [4,5], show excellent oxidation resistance at high temperatures. This is due to the formation of a protective $\mathrm{SiO}_{2}$ scale by selective oxidation of $\mathrm{Si}$. However, oxidation behavior of disilicides is generally complicated, especially depending on oxidation temperature. Therefore, oxidation mechanism for each disilicide has not been clarified yet.

In the present study, based on observation of structures of oxide scales formed on some disilicides, classification of oxidation behavior in disilicides was proposed and oxidation processes were discussed.

\section{Experimental}

Fabrication of specimen: Powders of disilicides such as $\mathrm{FeSi}_{2}, \mathrm{CoSi}_{2}, \mathrm{MoSi}_{2}, \mathrm{WSi}_{2}, \mathrm{CrSi}_{2}$, $\mathrm{NbSi}_{2}, \mathrm{TaSi}_{2}, \mathrm{VSi}_{2}$, and $\mathrm{ReSi}_{1.75}$, were sintered by applying a spark plasma sintering (SPS) method. In this sintering method, the each powder is packed in a graphite die (outer diameter: $25 \mathrm{~mm}$ and inner diameter: $15 \mathrm{~mm}$ ) under a compressive stress of $40 \mathrm{MPa}$, and then a pulsating current was passed through the powder and the graphite die in an evacuated chamber of $6 \mathrm{~Pa}$. The heating rate was $0.33 \mathrm{~K} / \mathrm{sec}$, and pulsating current was passed to heat up to each sintering temperature in which full densification of the disilicide can be achieved. Relative densities measured by Archimedean method were over $96 \%$ in all disilicides.

Oxidation tests: Specimens for oxidation tests were cut into about $4 \times 7 \times 1 \mathrm{~mm}$ pieces from the sintered compacts. The surfaces were polished to $1 \mu \mathrm{m}$ diamond finish, and then cleaned ultrasonically in acetone bath. Although oxidation tests were carried out in air at temperatures 
ranging from 773 to $1773 \mathrm{~K}$, the oxidation temperature range depends on the melting point and phase transformation temperature of each disilicide. Observation and analysis of oxide scales formed on the disilicides were performed with scanning electron microscopy (SEM), transmission electron microscopy(TEM), and electron probe microanalyzer (EPMA).

\section{Results and Discussion}

Prediction of oxidation mode: In oxidation of disilicides, selective oxidation of $\mathrm{Si}$ or simultaneous oxidation of metal and Si could be observed. Thus, the oxidation reactions are expressed as follows:

$$
\begin{aligned}
& 2 \mathrm{x} \cdot \mathrm{MeSi}_{2}+(8 \mathrm{x}+1) \cdot \mathrm{O}_{2} \rightarrow 2 \mathrm{Me}_{\mathrm{x}} \mathrm{O}+4 \mathrm{x} \cdot \mathrm{SiO}_{2} \\
& \mathrm{y} \cdot \mathrm{MeSi}_{2}+(2 \mathrm{y}-1) \cdot \mathrm{O}_{2} \rightarrow \mathrm{Me}_{\mathrm{y}} \mathrm{Si}+(2 \mathrm{y}-1) \cdot \mathrm{SiO}_{2}
\end{aligned}
$$

Which reaction is liable to occur would depend on thermodynamic (affinity of metal and silicon for oxygen) and kinetic (diffusivity of oxygen in oxide scale and silicon in disilicide) factors. Therefore, those factors must be considered for understanding oxidation mechanism of disilicides. Moreover, in the case that the metal oxide possesses a high vapor pressure, the evaporation must be considered. These factors in an oxidation process are illustrated in Fig. 1.

Fig. 2 shows a predicted oxidation model of disilicides. As a first step in predicting oxidation mode,

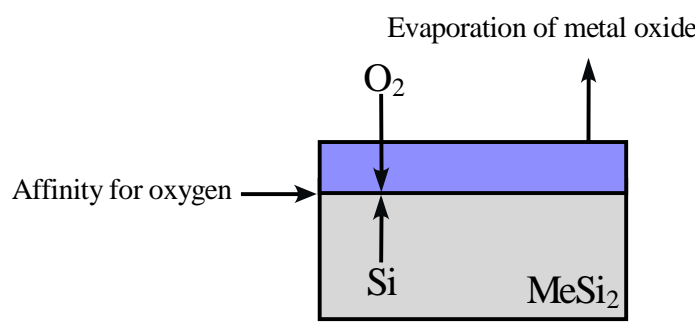

Fig.1 Thermodynamic and kinetic factors in oxidation of dislicide. we at first consider difference in affinity for oxygen between metal and Si. For the consideration, the following three cases are predicted.

(a) Affinity of Si for oxygen is much higher than that of metal: $\mathrm{FeSi}_{2}, \mathrm{CoSi}_{2}, \mathrm{MoSi}_{2}, \mathrm{WSi}_{2}, \mathrm{ReSi}_{1.75}$. In these disilicides, it is speculated that $\mathrm{Si}$ tends to be selectively oxidized, leading to formation of a $\mathrm{SiO}_{2}$ scale.

(b) Affinity of $\mathrm{Si}$ for oxygen is relatively close to that of metal: $\mathrm{NbSi}_{2}, \mathrm{TaSi}_{2}, \mathrm{CrSi}_{2}$. In these disilicides, it is speculated that selective oxidation of $\mathrm{Si}$ is hard to occur.

(c) Affinity of Si for oxygen is lower than that of metal: $\mathrm{VSi}_{2}, \mathrm{TiSi}_{2}, \mathrm{ZrSi}_{2}$.

In these disilicides, it is speculated that metal and Si tend to be simultaneously oxidized, leading to formation of a mixed oxide scale.

As the next step, diffusivity of $\mathrm{Si}$ in a disilicide and oxygen in an oxide scale must be considered. Even in the disilicides belonging to (a), sufficient supply of $\mathrm{Si}$ from a disilicide substrate, comparing with that of oxygen through a $\mathrm{SiO}_{2}$ scale, is required for continuous growth of a $\mathrm{SiO}_{2}$ scale. In other words, in disilicides which have high diffusivity of Si in the disilicides and low affinity of metal for oxygen, steady growth of a $\mathrm{SiO}_{2}$ scale is liable to occur.

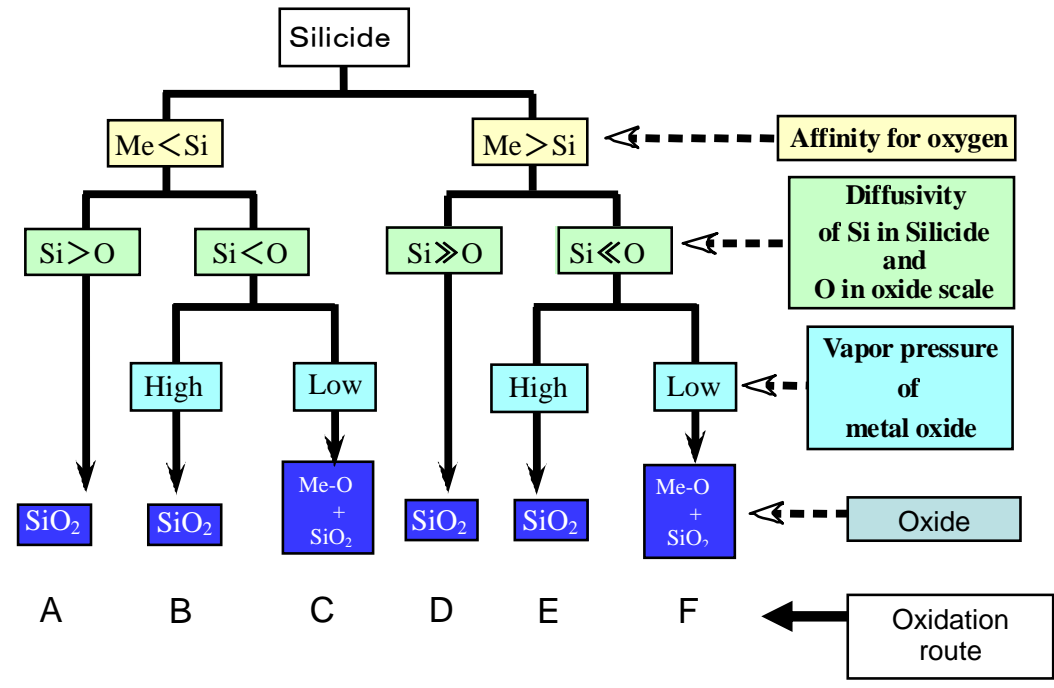

Fig. 2 Prediction of oxidation route in disilicides. 
Conversely, in disilicides which have low diffusivity of $\mathrm{Si}$ in the disilicides and high affinity of metal for oxygen, simultaneous formation of metal oxide and $\mathrm{SiO}_{2}$ is liable to occur.

In addition, when the metal oxide(s) formed on a disilicide possesses a high vapor pressure, it is speculated that evaporation of the metal oxide plays an important role in the formation of a $\mathrm{SiO}_{2}$ scale. That is to say, only $\mathrm{SiO}_{2}$, as a consequence of simultaneous formation of metal and silicon oxides and evaporation of the metal oxide in an early stage of oxidation, may remain on the disilicide. The vapor pressures of $\mathrm{MoO}_{3}, \mathrm{WO}_{3}$, and $\mathrm{Re}_{2} \mathrm{O}_{7}$ are appreciably high, and the high vapor pressure is particularly advantageous for forming a $\mathrm{SiO}_{2}$ scale.

Depending on the above factors, the oxidation process of each disilicide will take an oxidation route among A-F shown in Fig. 2.

Structure of oxide scale formed on disilicide: As qualitatively described above, structure of an oxide scale formed on a disilicide could be mainly decided by thermodynamic and kinetic factors and vapor pressure of metal oxide. However, data on those factors, especially data on diffusivity, are not necessarily sufficient. Therefore, in the present study, structures of oxide scales formed on various disilicides in a wide temperature range were observed.

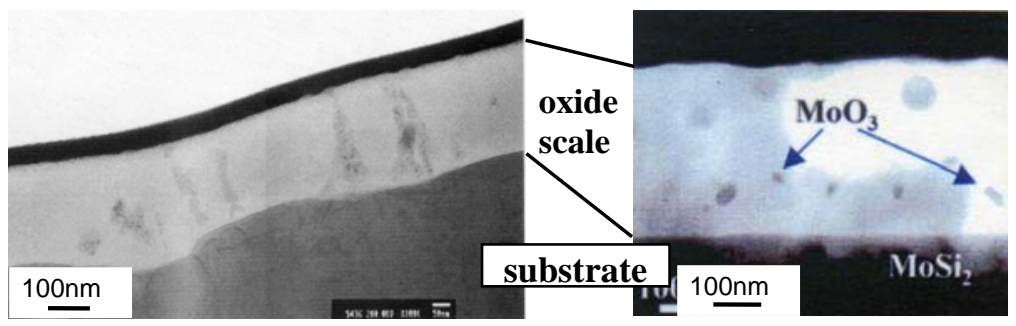

(a) $\mathrm{CoSi}_{2}$

(b) $\mathrm{MoSi}_{2}$

Fig. 3 TEM photographs of oxide scales formed on (a) $\mathrm{CoSi}_{2}$ for $360 \mathrm{ks}$ at $1373 \mathrm{~K}$ and(b) $\mathrm{MoSi}_{2}$ for $360 \mathrm{ks}$ at $1273 \mathrm{~K}$.

(1) Disilicide in which affinity of

Si for oxygen is much higher than that of metal

In oxidation of the disilicides belonging to this category, taking a route A or B can be expected. As an example, Fig. 3 shows cross-sectional TEM images of the oxide scales formed on $\mathrm{CoSi}_{2}$ at $1373 \mathrm{~K}$ and $\mathrm{MoSi}_{2}$ at $1273 \mathrm{~K}$ in air. It can be understood that each disilicide forms a $\mathrm{SiO}_{2} \mathrm{scale}$ almost completely at the oxidation temperature.

Structures of all oxide scales formed on $\mathrm{CoSi}_{2}$ in a temperature range of $773 \mathrm{~K}$ to $1373 \mathrm{~K}$ were similar to that in Fig. 3(a). $\mathrm{FeSi}_{2}$ also forms a complete $\mathrm{SiO}_{2}$ scale in a temperature range of $773 \mathrm{~K}$ to $1273 \mathrm{~K}$. Here, as maximum oxidation temperature for $\mathrm{CoSi}_{2}$ and $\mathrm{FeSi}_{2}$ was decided by considering melting point and phase transformation temperature, structures of oxide scales formed at higher temperatures were not observed. TEM observation of oxide scales in $\mathrm{CoSi}_{2}$ and $\mathrm{FeSi}_{2}$ demonstrates that $\mathrm{Si}$ is selectively oxidized to form a $\mathrm{SiO}_{2}$ scale. This may be caused by high diffusivity of $\mathrm{Si}$ in the disilicides and lower affinity of Co or Fe for oxygen comparing with Si. Consequently, it can be concluded that the oxidation process of $\mathrm{CoSi}_{2}$ and $\mathrm{FeSi}_{2}$ takes a route $\mathrm{A}$.

On the other hand, $\mathrm{MoSi}_{2}$ and $\mathrm{WSi}_{2}$ form a complete $\mathrm{SiO}_{2}$ layer at temperatures higher than $1273 \mathrm{~K}$ and $1573 \mathrm{~K}$, respectively, but these disilicides form a mixed oxide scale consisting of $\mathrm{SiO}_{2}$ and metal oxide $\left(\mathrm{MoO}_{3}\right.$ or $\left.\mathrm{WO}_{3}\right)$ at lower temperatures. An example of the oxide scale structure is demonstrated in Fig. 4 which shows the oxide scale formed on $\mathrm{MoSi}_{2}$ at 773 $\mathrm{K}$. The oxide scale consists of an amorphous

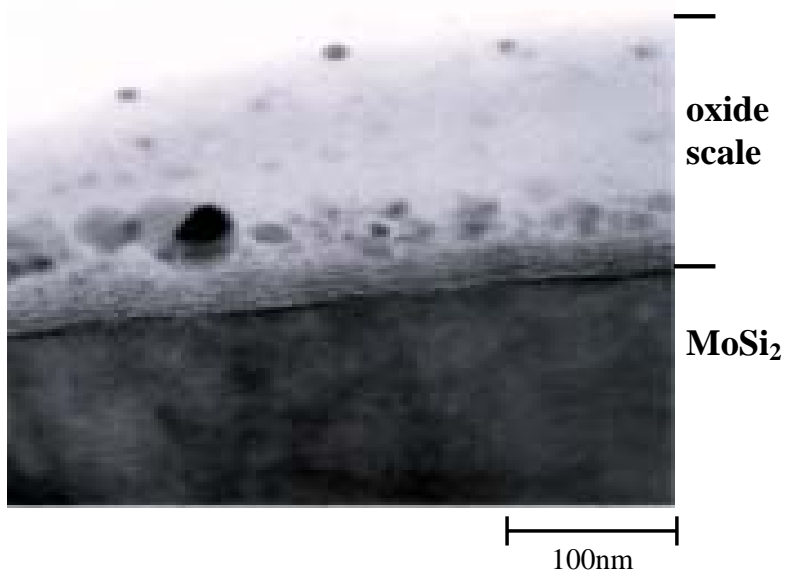

Fig. 4 TEM photograph of oxide scale formed on $\mathrm{MoSi}_{2}$ for $360 \mathrm{ks}$ at $773 \mathrm{~K}$. 
$\mathrm{SiO}_{2}$ scale containing a number of fine $\mathrm{MoO}_{3}$ particles. Similarly, WSi 2 also forms an mixed oxide scale consisting of $\mathrm{SiO}_{2}$ and $\mathrm{WO}_{3}$ in a low temperature region, as shown in Fig. 5. It can be seen in Fig. 5 that the oxide scales formed on $\mathrm{WSi}_{2}$ are grouped into 3 types, depending on oxidation temperature. At temperatures below $1073 \mathrm{~K}$, the oxide scales consist of the mixed oxides of $\mathrm{WO}_{3}$ and $\mathrm{SiO}_{2}$. In the intermediate temperature range, oxide scales having double-layer structure are formed. The outer and inner layers are consisting of $\mathrm{SiO}_{2}$ and the mixed oxides of $\mathrm{WO}_{3}$ and $\mathrm{SiO}_{2}$, respectively. At temperatures above $1573 \mathrm{~K}$, an oxide scale consisting of only $\mathrm{SiO}_{2}$ is formed. The formation of the outer $\mathrm{SiO}_{2}$ layer in the intermediate temperature range must be caused by evaporation of $\mathrm{WO}_{3}$. In other words, evaporation of $\mathrm{WO}_{3}$ plays an important role for the formation of a complete $\mathrm{SiO}_{2}$ layer.

At the moment when $\mathrm{WSi}_{2}$ is exposed to an oxidizing atmosphere, $\mathrm{W}$ and $\mathrm{Si}$ must be simultaneously oxidized to form $\mathrm{WO}_{3}$ and $\mathrm{SiO}_{2}$. In the case that the vapor pressure of $\mathrm{WO}_{3}$ is appreciably high, it is expected that only $\mathrm{SiO}_{2}$ is liable to be left on the substrate. In fact, the oxide scales formed at temperatures above $1573 \mathrm{~K}$ consisted of only $\mathrm{SiO}_{2}$. Once the substrate is covered with a protective $\mathrm{SiO}_{2}$ scale, only $\mathrm{SiO}_{2}$ grows in further oxidation. In other words, selective oxidation occurs. However, at lower temperatures, the evaporation rate was not enough to left only $\mathrm{SiO}_{2}$. Therefore, $\mathrm{WSi}_{2}$ forms a mixed oxide scale at low temperatures and a double layer oxide scale at intermediate temperatures.

Based on such structure of oxide scales formed in the intermediate temperature region, the requisite vapor pressure of metal oxide for formation of a complete $\mathrm{SiO}_{2}$ scale can be estimated. Our recent study on some disilicides demonstrated a clear relationship between vapor pressure

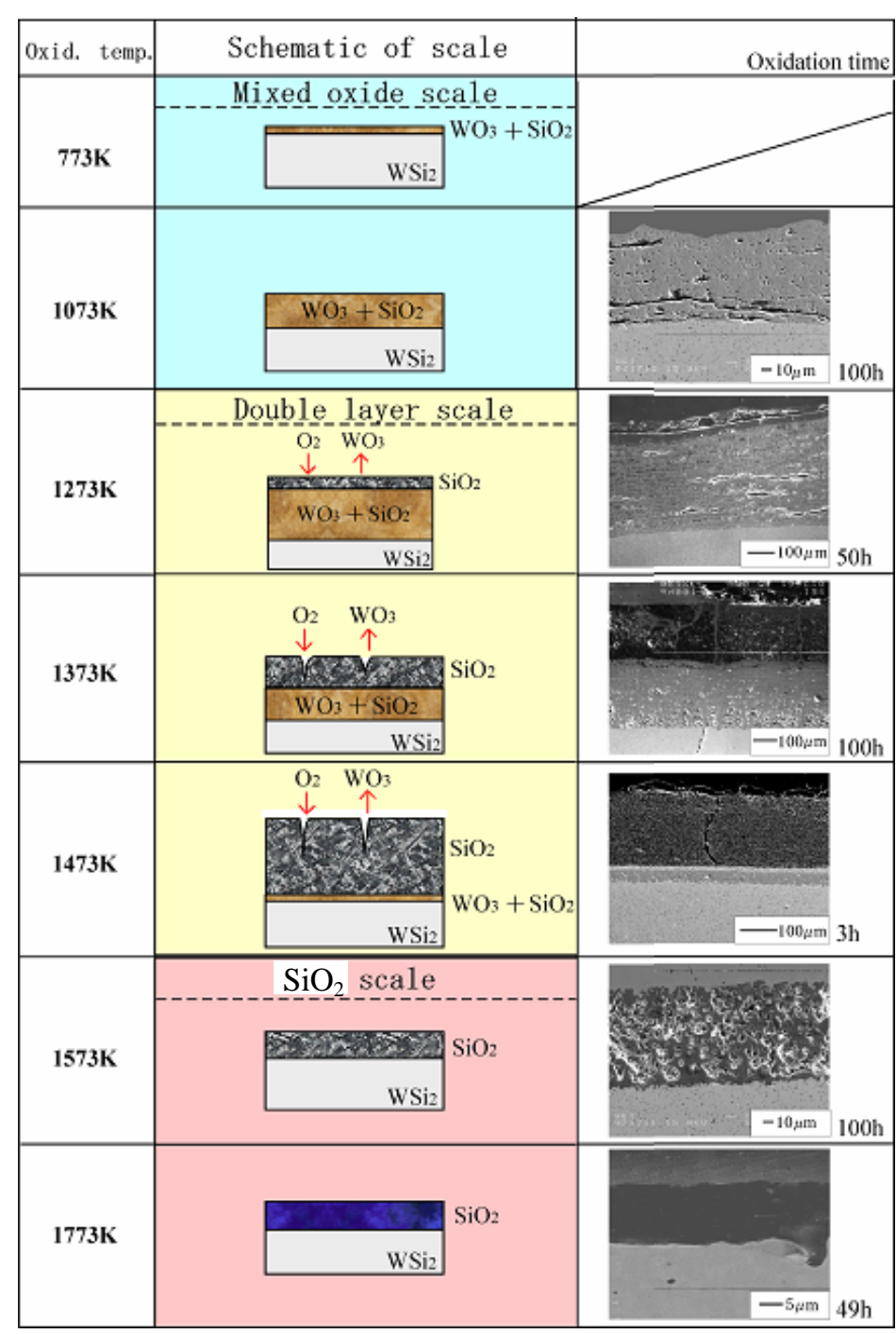

Fig. 5 Cross-sectional SEM photographs of oxide scales formed on $\mathrm{WSi}_{2}$ at various temperatures.

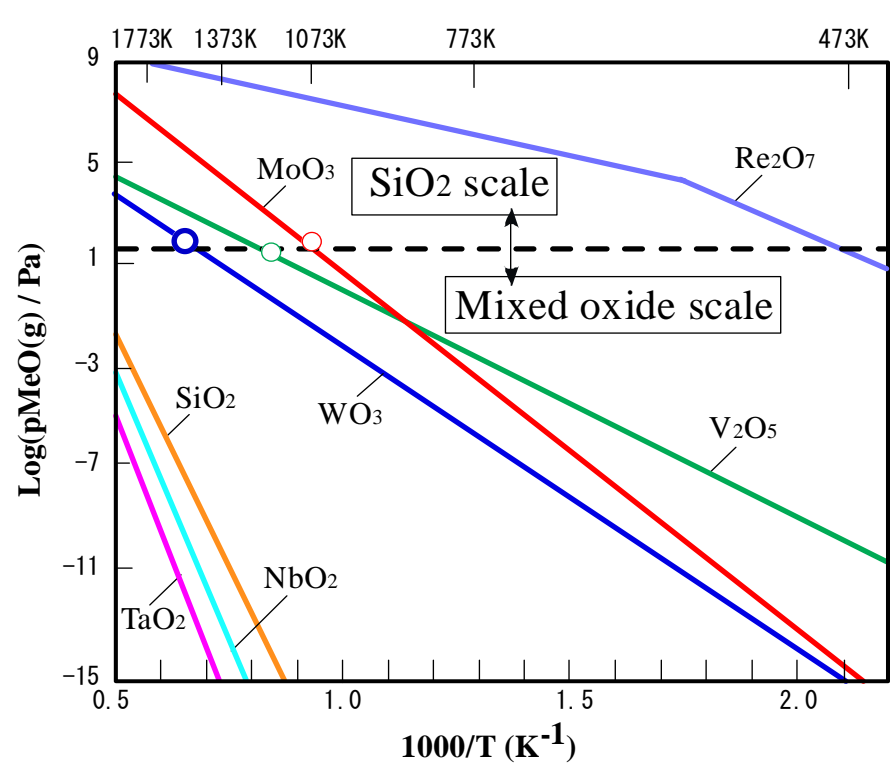

Fig. 6 Vapor pressure of various metal oxides. 
of a metal oxide and formation of a $\mathrm{SiO}_{2}$ scale [6]. The relationship is shown in Fig. 6, where open circles indicate the approximate transition temperatures from the formation of a double layer scale to that of a $\mathrm{SiO}_{2}$ scale. In $\mathrm{MoSi}_{2}, \mathrm{WSi}_{2}$ and $\mathrm{ReSi}_{1.75}$ in which each metal oxide possesses an appreciably high vapor pressure, a complete $\mathrm{SiO}_{2}$ scale can be formed when the vapor pressure reaches $10 \mathrm{~Pa}$. The temperature at which the evaporation pressure of $\mathrm{WO}_{3}$ reaches $10 \mathrm{~Pa}$ was estimated to be about $1500 \mathrm{~K}$, about $1100 \mathrm{~K}$ for $\mathrm{MoSi}_{2}$ and about $500 \mathrm{~K}$ for $\mathrm{ReSi}_{1.75}$.

From the results described above, it is concluded that the disilicides such as $\mathrm{MoSi}_{2}, \mathrm{WSi}_{2}$ and $\mathrm{ReSi}_{1.75}$ take a route $\mathrm{B}$ at high temperatures and take a oxidation route $\mathrm{C}$ at low temperatures.

(2) Disilicide in which affinity of Si for oxygen is relatively close to that of metal

In oxidation of the disilicides belonging to this category, taking a route $\mathrm{C}$ can be expected. In fact, $\mathrm{NbSi}_{2}$ formed a thick oxide scale consisting of mixed oxides of $\mathrm{Nb}_{2} \mathrm{O}_{5}$ and $\mathrm{SiO}_{2}$. Also in $\mathrm{TaSi}_{2}$, similar mixed oxide scale was formed.

(3) Disilicide in which affinity of Si for oxygen is lower than that of metal

In oxidation of the disilicides belonging to this category, taking a oxidation route $\mathrm{D}, \mathrm{E}$, or $\mathrm{F}$ can be expected. It was found that $\mathrm{VSi}_{2}$ took a route $\mathrm{F}$ at temperatures lower than $1173 \mathrm{~K}$ and a route $\mathrm{E}$ at temperatures higher than $1173 \mathrm{~K}$. According to literature[7-9], $\mathrm{TiSi}_{2}$ and $\mathrm{ZrSi}_{2}$ formed an oxide scale consisting of $\mathrm{TiO}_{2}$ or $\mathrm{ZrO}_{2}$ and $\mathrm{SiO}_{2}$, namely, these disilicides took a route $\mathrm{F}$.

The oxide scale structures formed on various disilicides are tabulated in Table 1 . In the table, serviceable temperature for each disilicide, which was predicted from oxide scale structure, is also shown.

Table 1 Structure of oxide scale on disilicide and oxidation resistance.

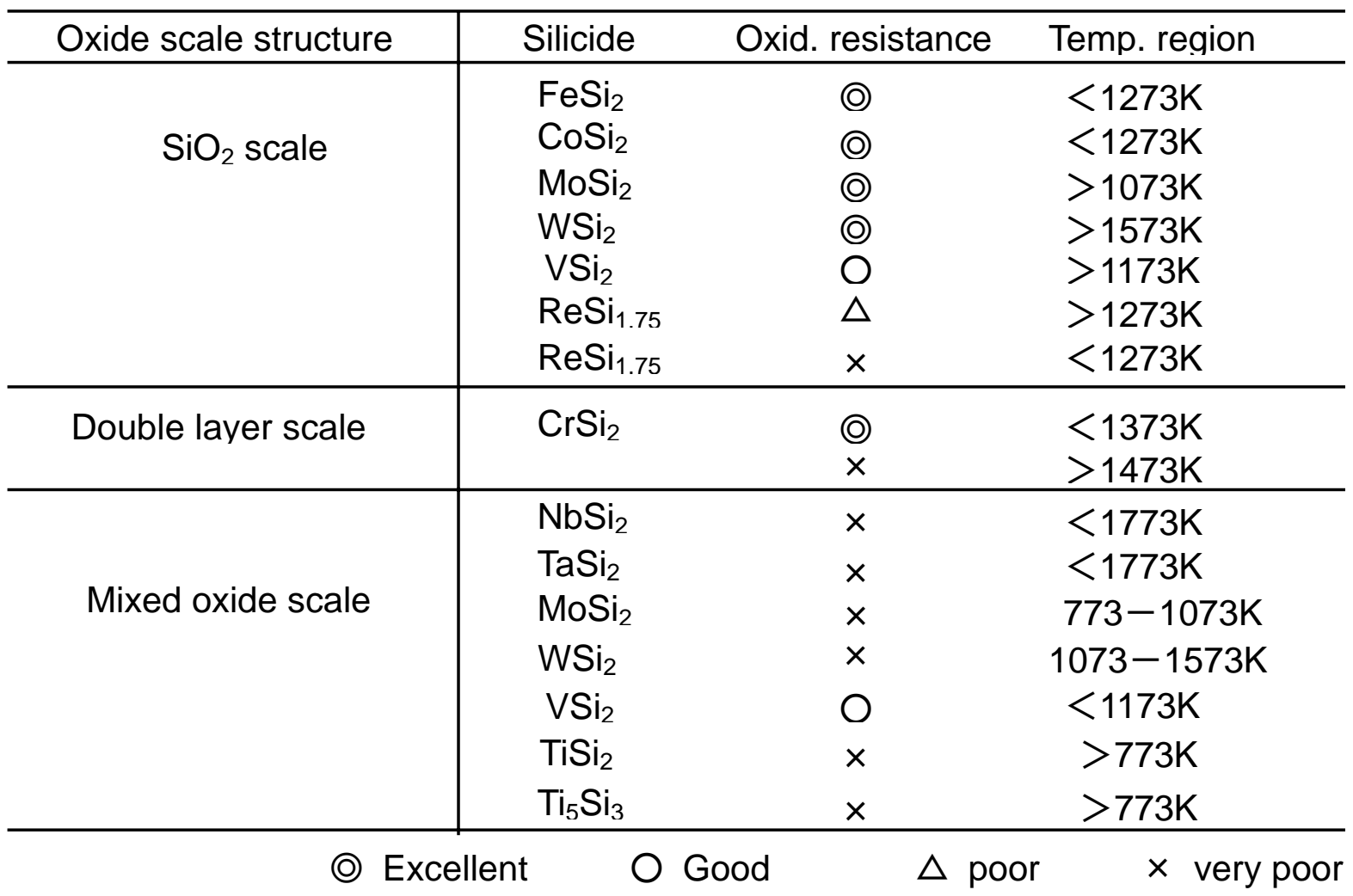




\section{Summary}

In the present study, structures of oxide scales formed on various disilicides were observed. The oxide scales formed on disilicides could be grouped into 3 types, (a) silica scale, (b) mixed oxide (silica+metal oxide) scale, and (c) double layered (silica/metal oxide) scale. Disilicides that form an oxide scale of the type of (a) generally show excellent oxidation resistance. As such disilicides, there were $\mathrm{FeSi}_{2}, \mathrm{CoSi}_{2}, \mathrm{MoSi}_{2}, \mathrm{WSi}_{2}$, etc. In $\mathrm{FeSi}_{2}$ and $\mathrm{CoSi}_{2}$ (oxidation route A), a protective silica scale was formed due to the selective oxidation of $\mathrm{Si}$, whereas as in $\mathrm{MoSi}_{2}$ and $\mathrm{WSi}_{2}$ (oxidation route $\mathrm{B}$ ) evaporation of metal oxide played an important role for the formation of a silica scale. $\mathrm{TaSi}_{2}$ and $\mathrm{NbSi}_{2}$ (oxidation route C) belonged to the type (b) and only $\mathrm{CrSi}_{2}$ the type (c). Oxidation processes of these disilicides were also discussed.

\section{References}

[1] O. Honingschmid: Monatsh. Chem., Vol. 28(1907), p. 1017.

[2] E. Fitzer: Proc. of the Second Plansee Seminar, Springer-Verlag, Wien (1955), p. 56.

[3] J. Cook, A. Kahn, E. Lee, and R. Mahapatra: Mat. Sci. Eng., Vol. A155(1992)., p. 183.

[4] L. N. Yefimenko, Y. P. Nechiporenko, and V. N. Pavlov: Fiz. Mtal. Metalloved., Vol. 16(1963), p. 931.

[5] K. Kurokawa, H. Matsuoka, and H. Takahashi: Maters. Sci. Forum, Vol. 251/254(1997), p. 885.

[6] K. Kuroakwa H. Hara, A. Shibayama, and H. Takahashi: High Temperature Materials, ed. S. C. Singhal, Electrochem. Soc. (2002), p. 240.

[7] F. N. Schwettmann, R. A. Graff, and M. Kolodney: J. Electrochem. Soc., Vol. 118(1971), p. 1973.

[8] A. Abba, A. Galerie, and M. Callet: Oxid. Met., Vol. 17(1982), p. 43.

[9] H. Jiang, C. S. Peterson, and M. A. Nicolet: Thin Solid Films, Vol. 140(1986), p. 115. 